Document downloaded from:

http://hdl.handle.net/10251/158945

This paper must be cited as:

Kozminska, A.; Al Hassan, M.; Wiszniewska, A.; Hanus-Fajerska, E.; Boscaiu, M.; Vicente, O. (2019). Responses of succulents to drought: Comparative analysis of four Sedum (Crassulaceae) species. Scientia Horticulturae. 243:235-242.

https://doi.org/10.1016/j.scienta.2018.08.028

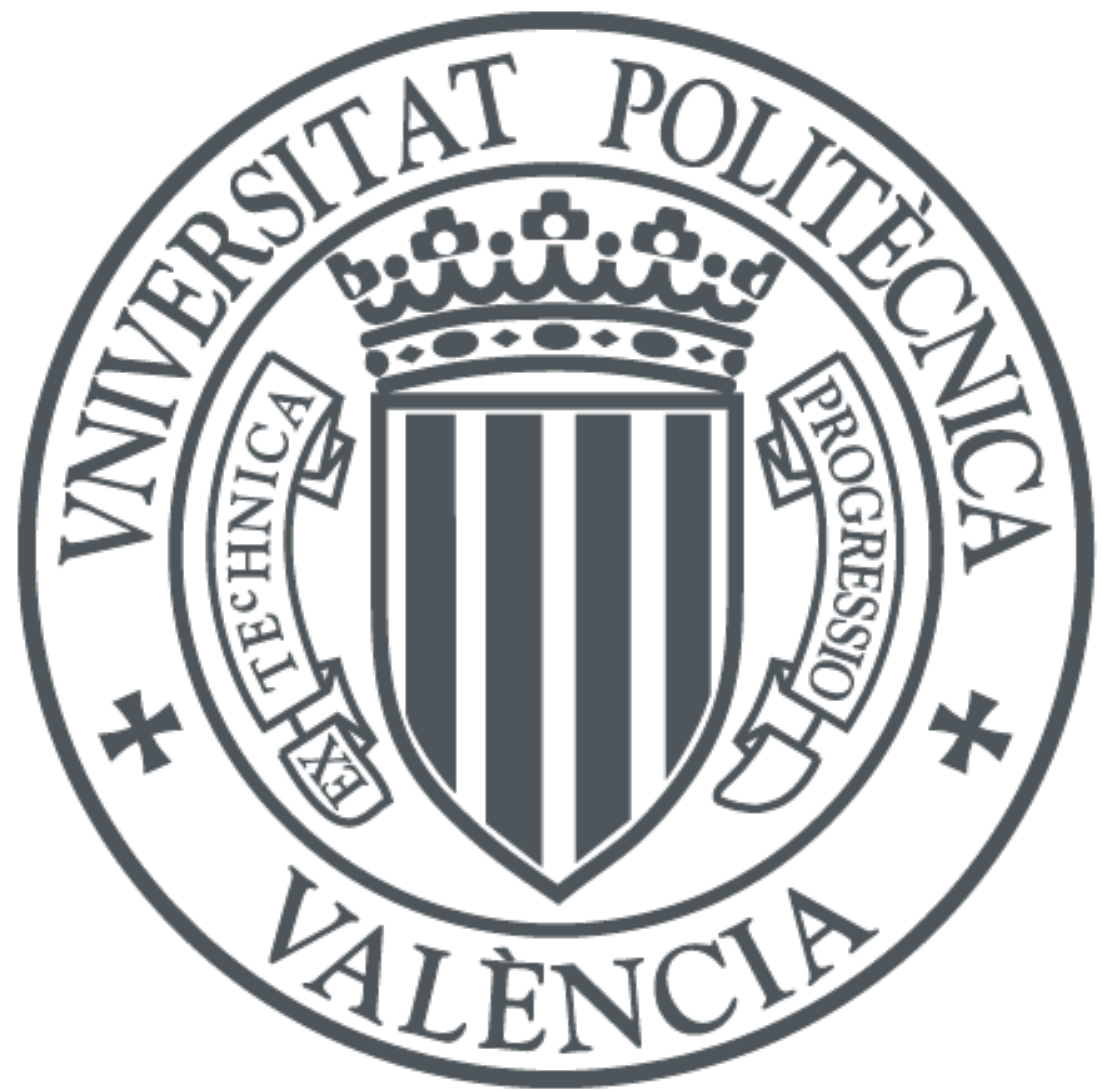

The final publication is available at

https://doi.org/10.1016/j.scienta.2018.08.028

Copyright Elsevier

Additional Information 


\title{
Responses of succulents to drought: comparative analysis of four Sedum (Crassulaceae) species
}

Aleksandra Kozminska ${ }^{a, b^{*}}$, Mohamad Al Hassan ${ }^{a, c}$, Alina Wiszniewska ${ }^{b}$, Ewa HanusFajerska $^{b}$, Monica Boscaiu ${ }^{d}$, Oscar Vicente ${ }^{a}$

${ }^{a}$ Institute of Plant Molecular and Cellular Biology (IBMCP, UPV-CSIC), Universitat Politècnica de València, Camino de Vera s/n, 46022, Valencia, Spain

${ }^{\mathrm{b}}$ Unit of Botany and Plant Physiology of Institute of Plant Biology and Biotechnology, Department of Biotechnology and Agriculture, University of Agriculture in Krakow, 31-425 Krakow, Al. 29 Listopada 54, Poland (permanent address)

${ }^{\mathrm{c}}$ Present address: The New Zealand Institute for Plant \& Food Research Limited (PFR), Mt Albert Research Centre, Private Bag 92169, Auckland, New Zealand (present address)

${ }^{\mathrm{d}}$ Mediterranean Agroforestry Institute (IAM, UPV), Universitat Politècnica de València, Spain, Camino de Vera s/n, 46022, Valencia, Spain

*corresponding author e-mail: akozminska@ogr.ur.krakow.pl

\begin{abstract}
The increased frequency and intensity of drought periods is becoming a serious thread for agriculture, prompting the identification of crop species and cultivars with enhanced water stress tolerance. Drought responses were studied in four ornamental Sedum species under controlled greenhouse conditions, by withholding watering of the plants for four weeks. Determination of growth parameters (stem length, fresh weight) allowed establishing the relative degree of tolerance of the selected species as $S$. spurium $>$ S. ochroleucum $>S$. sediforme $>$ S. album. The levels of photosynthetic pigments (chlorophylls a and $\mathrm{b}$ and total carotenoids), oxidative stress [using malondialdehyde (MDA) as marker], non-enzymatic antioxidants (total phenolic componds and total flavonoids) and osmolytes (proline and total soluble sugars) were measured in leaves of control and stressed plants, to correlate drought tolerance with the activation of specific response mechanisms. The results obtained indicate that a higher tolerance to water deficit in Sedum is associated with: a) relatively lower stressinduced degradation of chlorophills and carotenoids, especially of the latter (which does not decrease in water-stressed plants of $S$. spurium, the most tolerant species); b) no increase in MDA levels; that is, lack of drought-induced oxidative stress and, consequently, no
\end{abstract}


requirement to activate the synthesis and accumulation of antioxidant compounds; and c) higher proline levels in the non-stressed controls, which could be the basis of constitutive mechanisms of tolerance. However, proline concentrations are too low to have any significant osmotic effect, and its likely contribution to water deficit resistance in Sedumwould be due to its activity as 'osmoprotectant'. The identification of these biochemical markers of drought tolerance should help to develop rapid and efficient screening procedures to select Sedum taxa with enhanced tolerance when comparing different species within the genus, or different cultivars within a given species.

\section{Abbreviations}

Caro - total carotenoids

Chl a - chlorophyll a

Chl b - chlorophyll b

MDA - Malondialdehyde (MDA),

Pro - Proline

TSS - Total soluble sugars

TPC - Total phenolic compunds

TF - Total flavonoids

\section{Keywords}

succulence; water deficit; osmolytes; antioxidants; growth response

\section{Introduction}

The frequency and intensity of drought periods has dramatically increased in the last decades, especially in many arid and semiarid regions of the world, including the Mediterranean Basin (Giannakopoulos et al., 2009; Cai et al. 2015, Lopez-Nicolas et al. 2018, Ortega-Gómez et al. 2018). Drought adversely affects the physiological and biochemical status of plants (Chaves and Oliveira 2004; Osakabe et al. 2014), and is one of the most challenging stress factors currently encountered by global ecosystems (Bartlett et al. 2012; Sandoval et al. 2016). Even a slight destabilisation in cell water balance may negatively affect physiological processes associated with plant growth and, for cultivated species, with crop yields (Mathur et al. 2014; Nxele et al. 2018). Drought, similarly to many abiotic stresses, causes cell dehydration and 
the enhanced generation of reactive oxygen species (ROS). ROS are continuously produced in plants as by-products of aerobic metabolism, but under stress conditions their concentrations largely increase leading to oxidative stress (Ahmad et al. 2010; Talukdar 2013; You and Chan 2015). To survive drought and other abiotic stress conditions, plants activate a series of conserved mechanisms to minimise possible injuries caused by those stress factors. One of these general responses to water deficit involves the maintenance of cellular osmotic balance, based on the synthesis and accumulation in the cytoplasm of compatible solutes or 'osmolytes', to avoid cellular dehydration (Szabados and Savoure 2010; Talukdar 2013; Per et al. 2017). Osmolytes, such as soluble sugars or some amino acids, play also the role of osmoprotectants in the responses to stress, maintaining the fluidity of plasma membranes and the proper activity of enzymes (Blum 2011; Rabbani and Choi 2018) by directly stabilising macromolecular structures as low-molecular-weight chaperons. Another common reaction to water stress is the activation of antioxidant systems, both enzymatic and non-enzymatic, to counteract oxidative damage caused by ROS (Apel and Hirt 2004; Chen 2007; Das and Roychouhury 2014). Among non-enzymatic antioxidants, phenolic compounds, including flavonoids, have been shown to be synthesized in many plant species as a response to water deficit (Sanchez-Rodriguez et al. 2011; Bautista et al., 2016).

Comparing information on the reaction of different species to water stress regarding growth parameters and biochemical markers allows distinguishing genotypes that are resistant or susceptible to this stress (Gholami et al. 2012; Ji et al. 2012; Nxele et al. 2017). Furthermore, such comparative studies, correlating the activation of specific stress responses and the relative tolerance of genetically related taxa (for example, different species of the same genus, different varieties or cultivars of the same species) provide insight into the mechanisms of tolerance to abiotic stress in plants (Gil et al. 2013; Sandoval et al. 2016; Cicevan et al. 2016; Al Hassan et al. 2017)

Sedum L. is one of the largest species-rich genus of the stonecrop family (Crassulaceae DC., Crassuloidae, Saxifragales), comprising about 450 species assigned to thirty sections (Thiede and Egelli 2007; Thorne and Reveal 2007, The Plant List, 2013), or when subgenus Sedum is delineated - about 320 species (Niculin et al. 2016). This genus mostly consists of branched, multi-stem perennial succulent herbs, occasionally sub-shrubs, which are not considered invasive. Sedum species have a wide geographic distribution; they are primarily growing in arid environments on shallow soils on stony or gravel stands, mainly in temperate to subtropical regions. Thus, the diversity of the genus representatives is high in the 
Mediterranean region, followed by America (mainly Central America), the Himalayas, and East Asia (Stephenson 1994; Thiede and Eggli 2007). Phytochemical screening has shown that sedums are an excellent source of a variety of secondary metabolites, including condensed tannins, alkaloids, flavonoids, free sugars, cyanogenic compounds, and triterpenoids, which are considered to play a major role in plant tolerance to biotic and abiotic stresses (Stevens et al. 1994; Stevens et al. 1996; Han and Zhao 2005; Al-Qudah et al. 2012; $\mathrm{Xu}$ et al. 2015).

Species belonging to this genus are distinctive in growing in dense clumps, with succulent stems and leaves, and rose, yellowish or creamy to white tiny flowers arranged in showy inflorescences. Numerous cultivars are well-known ornamental plants due to their attractive appearance and hardiness. They are ideal for sunny environments that get too little water, and are frequently used as ground covers or rock gardens because of their limited height (Stephenson 1994, Pudelska and Rojek 2015). Moreover, Sedum are slow-growing plants that survive long periods without water, yet they can grow faster when water is available (Durhman et al. 2006; Carter and Butler 2008; Nektarios et al. 2015). The economic importance and horticultural interest in this genus has increased in recent years due to its suitability to be used in the so-called 'green roofs', a sustainable and economically sound strategy to mitigate environmental problems in urban areas, namely to counteract air pollution and the effect of urban heat islands (Getter and Rowe 2004; Van Mechelen et al. 2014; Vijayaraghavan 2016; Vahdai et al. 2017). Sedums are generally considered among the best plant species for extensive green roof technology due to their growth habit, shallow root system and drought tolerance, although different taxa may differ in their adaptability to this special environment (Damas et al. 2010; Nagase and Dunnett 2010; Starry et al. 2014; Nektarios et al. 2015). Therefore, a comparative evaluation of drought responses in various Sedum species would facilitate selection of the most suitable genotypes to be used as ornamentals for 'green roofs' under conditions of limited water availability.

In this study we have analysed the responses to water stress, under controlled greenhouse conditions, of four species: Sedum spurium, S. ochroleucum, S. album and S. sediforme, all possessing valuable ornamental traits. Inhibition of growth was used as a criterion to establish their relative degree of drought tolerance. To gain insight into the mechanisms of tolerance to water deficit in Sedum, we have also determined the levels of several biochemical markers associated to specific stress responses: proline and total soluble sugars (as osmolytes possibly involved in maintenance of cellular osmotic balance), malondialdehyde (MDA, a reliable 
marker of oxidative stress), beside total phenolic compounds and favonoids, as examples of non-enzymatic antioxidants.

\section{Material and methods}

\subsection{Plant material and stress treatment}

Seeds of the selected species: Sedum spurium, S. ochroleucum, S. album and S. sediforme, were purchased from the company B\&T World Seeds (Paguignan, France).

Seeds were sown directly into a moistened mixture of peat (50\%), perlite $(25 \%)$ and vermiculite $(25 \%)$ in $1 \mathrm{~L}$ pots $(\varnothing=11 \mathrm{~cm})$. The substrate was kept moderately moist, using Hoagland's nutrient solution (Hoagland and Arnon, 1950). Two months after seedling emergence, a water stress treatment was initiated by stopping watering the plants. Control plants grown in parallel were watered twice a week $(125 \mathrm{~mL}$ per pot). All experiments were conducted in a growth chamber with controlled environment, under the following conditions: long-day photoperiod (16 h of light, obtained by supplementing natural light with artificial light), temperature of $23^{\circ} \mathrm{C}$ during the light period and $17^{\circ} \mathrm{C}$ during the dark period. Air relative humidity ranged between $60 \%$ and $70 \%$ during the course of the experiment.

\subsection{Growth parameters}

After four weeks of treatment, when water-stressed plants appeared to be already affected, all plants were harvested and the following growth parameters were determined: total stem length (SL; cm), fresh weight of the leaves (FW; g), dry weight of the leaves, after incubation in an oven at $65^{\circ} \mathrm{C}$ for $48-72 \mathrm{~h}(\mathrm{DW}, \mathrm{g})$, and water content percentage (WC\%) (Gil et al. 2014). WC\% was calculated by the following formula: $\mathrm{WC} \%=[(\mathrm{FW}-\mathrm{DW}) / \mathrm{FW}] \times 100$.

Since plants of the studied Sedum species somewhat differ in size, to compare the effects of water deficit on plant growth of the different taxa, SL and FW of water-stressed plants were expressed as percentage of the average values of the corresponding controls, taken as $100 \%$ in each case: $10.47 \mathrm{~cm}$ and $8.63 \mathrm{~g}($ S. spurium $) ; 10.05 \mathrm{~cm}$ and $9.97 \mathrm{~g}(S$. ochroleucum), $7.95 \mathrm{~cm}$ and $6.55 \mathrm{~g}$ (S. album) and $8.40 \mathrm{~cm}$ and $3.67 \mathrm{~g}$ (S. sediforme), respectively.

\subsection{Biochemical analyses}

\section{Photosynthetic pigments}


Chlorophyll content and total carotenoids were determined following Lichtenthaler and Wellburn (1983). In short, fresh plant material was crushed and extracted with $80 \%$ acetone pre-cooled at $-20^{\circ} \mathrm{C}$, vortexed and centrifuged. The supernatant was collected and its absorbance was measured at $663 \mathrm{~nm}, 646 \mathrm{~nm}$, and $470 \mathrm{~nm}$, using a Cadex model SB038 spectrophotometer (Cadex, Saint-Jean-sur-Richelieu, Quebec, Canada). The concentration of each group of compounds was calculated according to the following equations (Lichtenthaler and Wellburn 1983):

Chlorophyll a $\left(\mathrm{chl} \mathrm{a} ; \mu \mathrm{g} \cdot \mathrm{ml}^{-1}\right)=12.21 \mathrm{~A}_{663}-2.81 \cdot \mathrm{A}_{646}$;

Chlorophyll b $\left(\mathrm{chl} \mathrm{b} ; \mu \mathrm{g} \cdot \mathrm{ml}^{-1}\right)=20.13 \cdot \mathrm{A}_{646}-5.03 \cdot \mathrm{A}_{663}$;

Total carotenoids $\left(\mu \mathrm{g} \cdot \mathrm{ml}^{-1}\right)=\left(1,000 \cdot \mathrm{A}_{470}-3.27 \cdot[\mathrm{chl} \mathrm{a}]-104 \cdot[\mathrm{chl} \mathrm{b}]\right) / 229$.

The calculated values were finally converted to $\mathrm{mg} \cdot \mathrm{g}^{-1} \mathrm{DW}$.

\section{Oxidative stress marker/Lipid peroxidation}

Malondialdehyde (MDA), a final product of membrane lipid peroxidation and a reliable marker of oxidative stress (Del Rio et al. 2005), was determined as reported by Hodges et al. (1999). Dried leaf material was extracted in 80\% methanol, in a rocker shaker, for 24-48 h. Methanol extracts were mixed with $0.5 \%$ thiobarbituric acid (TBA) prepared in $20 \%$ trichloroacetic acid (TCA) - or with 20\% TCA without TBA for the controls - and then incubated at $95{ }^{\circ} \mathrm{C}$ for $20 \mathrm{~min}$. After stopping the reaction on ice and centrifuging the samples, the absorbance of the supernatant was measured at $532 \mathrm{~nm}$. The non-specific absorbance at 600 and $440 \mathrm{~nm}$ was subtracted and MDA concentration was calculated using the equations described by Hodges et al. (1999).

\section{Non-enzymatic antioxidants}

Total antioxidant flavonoids (TF) were determined following the method described by Zhishen et al.(1999), by mixing the leaf methanol extracts with sodium nitrite, followed by aluminum chloride and sodium hydroxide. Absorbance was measured at $510 \mathrm{~nm}$, and the TF amount was expressed in equivalents of catechine, used as standard (mg eq. $\mathrm{C} \cdot \mathrm{g}^{-1} \mathrm{DW}$ ). This assay specifically detects aromatic rings bearing a catechol group, which includes most flavonoids but also some non-flavonoid phenolics, such as caffeic acid. Nevertheless, all these 
metabolites are characterised by being strong antioxidants (Zhishen et al. 1999) and, to simplify, we refer to the $\mathrm{AlCl}_{3}$-reactive compounds simply as 'total flavonoids'. Total phenolic compounds (TPC) contents in leaves were quantified as described in Blainski et al. (2013), by reaction with the Folin-Ciocalteu reagent. The extracts were mixed with the reagent and sodium bicarbonate and left in the dark for $90 \mathrm{~min}$. Absorbance was recorded at $765 \mathrm{~nm}$, and the results expressed in equivalents of gallic acid, used as standard (mg eq. $\left.\mathrm{GA} \cdot \mathrm{g}^{-1} \mathrm{DW}\right)$.

\section{Osmolytes}

Proline (Pro) concentration was quantified using dry leaf material, according to the ninhydrinacetic acid method of Bates et al. (1973). Free Pro was extracted in 3\% aqueous sulfosalicylic acid, and mixed with acid ninhydrin solution; the samples were incubated for $1 \mathrm{~h}$ at $95{ }^{\circ} \mathrm{C}$, cooled on ice and then extracted with toluene. Absorbance of the supernatant was read at 520 $\mathrm{nm}$, using toluene as a blank. Pro concentration was expressed as $\mu \mathrm{mol} \mathrm{g} \mathrm{g}^{-1} \mathrm{DW}$.

Total soluble sugars (TSS) were measured according to the method described by Dubois et al. (1956). Dried material was ground and mixed with $80 \%$ methanol on a rocker shaker for 24$48 \mathrm{~h}$. Sulfuric acid and 5\% phenol were added and mixed before absorbance readings were taken at $490 \mathrm{~nm}$. TSS contents were expressed as 'mg equivalent of glucose' per gram of DW.

\subsection{Statistical analyses}

Data were analyzed using the program Stagraphics Centurion v. XVI (Statpoint Technologies, Warrenton, Virginia, USA). The mean and standard deviation (SD) were calculated from four replicates per genotype and treatment (except for stem length, in which nine replicates were used). Mean values per species were calculated and the corresponding SD was calculated using cultivar means. The significance of the differences among control and drought stress treatments (expressed in percentage of variation over the control) for each species and between species for each treatment was evaluated with Student's t test.

\section{Results}

\subsection{Growth inhibition under water deficit conditions}


Water stress inhibited growth of the four investigated Sedum species (Fig. 1) although, in S. spurium and S. ochroleucum, no significant change in the length of the plant stems was detected in the drought stressed plants, as compared to the corresponding controls; on the other hand, the water stress treatment resulted in relative reductions of $36 \%$ of the control in S. album and of $30 \%$ in S. sediforme (Fig. 1A). The effect of drought was more clearly observed considering the fresh weight of the plant shoots, which were significantly reduced with respect to the corresponding controls in the four Sedum species. Here again, S. album appeared to be the taxon most affected by drought, with a relative $\mathrm{FW}$ reduction of $>80 \%$ of the control, followed by S. sediforme (67\%); biomass accumulation was reduced by ca. $50 \%$ in the other two Sedum species, S. spurium and S. orcholeucum. The four taxa were shown to be quite resistant to drought-induced leaf dehydration. The leaves of control plants contained a very high proportion of water, $96-97 \%$ of the fresh weight - in agreement with their succulent character - and no significant reduction in water content was observed in waterstressed plants (Fig. 1C). Therefore, the relative reduction in FW was indeed due to growth inhibition under water deficit conditions, and not merely to loss of water during the stress treatment.

\subsection{Photosynthetic pigments degradation}

Significant differences in the content of photosynthetic pigments - chlorophylls a and $\mathrm{b}$ and total carotenoids - were generally found in the leaves of untreated control plants, with the highest mean values measured in $S$. spurium, followed by $S$. orcholeucum; the species which showed the lowest pigments levels, about $50 \%$ of those determined for S. spurium, was S. sediforme (Fig 2). Water stress caused a significant reduction in all analysed pigment contents, and in the four selected Sedum species, except for carotenoids in S. spurium (Fig. $2 \mathrm{~A}, \mathrm{~B})$. The highest reductions (55\%- $60 \%$ of the corresponding controls) were observed in S.album, whereas the smallest relative decreases were measured in $S$. orcholeucum for chl a concentration (23\%) and in S. sediforme for chl b and carotenoids (13\%) (Fig. 2A, B).

\subsection{Oxidative stress and antioxidant compounds}

Leaf malondialdehyde (MDA) content varied in untreated control plants of the investigated species, from $28 \mathrm{nmol} \mathrm{g}^{-1} \mathrm{DW}$ in $S$. sediforme or $39 \mathrm{nmol} \mathrm{g}^{-1} \mathrm{DW}$ in $S$. album, to about 50 nmol g-1 DW in S. spurium and S. ochroleucum (Fig. 3A). Under water deficit conditions, these values increased significantly only in plants of $S$. album, which showed leaf MDA 
levels twice as high as in untreated control plants. In the other three Sedum species, MDA levels were not affected by the water stress treatment (Fig. 3A).

Regarding total phenolic compounds, their contents in leaves of control plants also differed when comparing the four studied Sedum species, with the lowest value measured in $S$. ochroleucum ( 1.6 mg eq G.A. $\left.\mathrm{g}^{-1} \mathrm{DW}\right)$ and the highest in S. spurium ( 3.5 mg eq G.A. $\mathrm{g}^{-1}$ DW); here again, S. album was the only taxon that significantly increased TPC levels, about 3.5-fold, as a response to drought (Fig. 3B). No significant changes in leaf TPC contents were detected in the other three Sedum taxa (Fig. 3B). Sedum album was also the species which accumulated the highest leaf TF levels, $10.6 \mathrm{mg}$ eq C. $\mathrm{g}^{-1} \mathrm{DW}(2.5$-fold more than in the untreated control), followed by $S$. sediforme, $6.8 \mathrm{mg}$ eq C. $\mathrm{g}^{-1} \mathrm{DW}$ (1.3-fold higher than the control); no significant changes were observed in S. spurium and S. ochroleucum, which were also the species with the lowest TF contents under non-stress conditions (Fig. 3C).

\subsection{Accumulation of osmolytes}

Proline (Pro), probably the most ubiquitous osmolyte in plants, was detected in the leaves of both untreated and water-stressed plants of all investigated Sedum species (Fig. 4A). Pro levels increased as a response to the water deficit in S. album ( 2-fold) and in S. sediforme ( 1.5-fold), but no significant variation was observed in S. spurium and S. ochroleucum. It should be noted, however, that the latter two species contained higher Pro levels in the nonstressed controls, so that absolute Pro contents after the water stress treatment were similar and quite low - in all four species, between 14 and $16 \mu \mathrm{mol} \mathrm{g}^{-1} \mathrm{DW}$ (Fig. 4A).

Stress-induced changes in total soluble sugars (TSS) contents in Sedum plants showed a qualitative pattern similar to that of Pro: an increase in $S$. album (3.5-fold) and in $S$. sediforme (1.8-fold) when comparing water-stressed plants with the controls, and no significant change in S. spurium and S. ochroleucum (Fig. 4B).

\section{Discussion}

In this study, we have analysed possible differences in the responses of four Sedum species to drought stress. The evaluated species originated from different regions of the world, and have developed adaptations to drought. S. spurium, exhibiting the highest tolerance to water deficit under our experimental conditions, is of Caucasian origin, and easily grows in full sun on both, well-drained and dry soils (Nagase et al. 2010; Vahdati et al. 2017). Another tolerant species, S. ochroleucum, is common in the Mediterranean Basin, and is mainly distributed 
from Spain and southern France to the Balkan Peninsula (Jalas et al. 1999; Hart and Bleij 2003). Sedum album - the species which proved to be the most drought-sensitive in our experiments - is native to Central Europe and is widespread throughout the whole continent (Stephenson 1994; Bachereau et al. 1998). Sedum sediforme, which is native to mountainous regions of southwestern Europe, has been considered as drought tolerant, even if it prefers rather moist stands (Damas et al. 2010; Van Mechelen et al. 2014). Notwithstanding succulence, which is the only common trait of all studied genotypes, our results showed the different sensitivity of sedums to prolonged water deficit, as it has been already reported by Nagase and Dunnet (2010) and Kuronuma and Watanabe (2017).

. Inhibition of growth is a common plant response to prolonged water stress, and may provide a reliable ranking of the relative degree of drought tolerance of different genotypes ( $\mathrm{Ji}$ et al. 2012; Hastilestari et al. 2013, Yooyongwech et al. 2013). In our case, among the evaluated growth parameters, 'fresh weight' turned out to be the most sensitive to drought, as it was reduced upon the water stress treatment in all four species, whereas a relative reduction of stem length was observed only $S$. album and S. sediforme. On the basis of growth inhibition, the relative tolerance to water deficit of the investigated Sedum species could be ordered as: S. spurium $>$ S. ochroleucum $>$ S. sediforme $>$ S. album.Chlorophyll contents also decreased in all taxa, and the relative degradation of chl a and chl b roughly corresponded with the relative drought tolerance of the four species, since the strongest reduction occurred in the most sensitive species; that is, in S. album. Moreover, absolute chlorophylls concentrations in the water stressed-plants were higher in the more tolerant $S$. spurium and $S$. ochroleucum, and lower in the more sensitive S. sediforme and S. album. Stress-induced changes in total carotenoid levels in leaves showed a similar pattern than those of chlorophylls, except that they did not decrease in water-stressed plants of the most tolerant $S$. spurium. Some of these results were similar to those reported by Mori (2009) concerning three other Sedum species. Contrary to our results, however, Shoohstarian et al. (2011) observed an increment of chlorophyll content in response to water stress in different species, including S. spurium and S. album. This was explained as a drought tolerance mechanism of these plants, which we could not reproduce.

A reduction of chlorophyll levels under stress - which is due to both, inhibition of its synthesis and activation of its degradation - is often related to enhanced oxidative stress in the course of partial cell dehydration (Mori et al. 2009; Liu et al. 2011; Gholami et al. 2012). MDA content has been used as a reliable indicator of oxidative damage (Del Rio et al. 2005; 
Farooq et al. 2009). Under drought, overproduction of ROS increases the concentration of malondialdehyde, which is the final product of membrane lipid peroxidation (Khan and Naqvi 2010). There is evidence that genotypes of contrasting tolerance to water stress differ in their MDA levels, and sensitive genotypes generally accumulate this compound at higher concentrations than tolerant ones (Basu et al. 2010; Anjum et al. 2012; Wang et al. 2012; Devi and Giridhar 2015). In this respect, a significant increase of MDA content under water stress conditions was observed only in S. album, the taxon most sensitive to drought. No changes in MDA levels were detected in the other three species, S. spurium, S. ochroleucum and $S$. sediforme, indicating that they were not affected by oxidative stress under water deficit conditions. They must, therefore, possess efficient defence mechanisms to avoid generation of ROS. Accordingly, a strong increase in the levels of antioxidant compounds, such as total phenolics or, specifically, total flavonoids, was only detected in water-stressed S. album plants - except for a small (but still significant) increase of TF contents in S. sediforme, the second most drought-sensitive of the analysed taxa. It seems logical to assume that the synthesis of these antioxidants is activated as a response to oxidative stress in the more sensitive species, but it is not necessary in the more tolerant $S$. spurium and S. ochroleucum. Apart from the antioxidant defence, plants activate mechanism of osmotic adjustment under stress, including the synthesis of osmolytes to protect cells from dehydration (Thomas 1997); proline accumulation is one of the most general responses of plants to drought, as Pro is the major functional osmolyte in many species (Hare et al 1999). For example, Selahvarzi et al. (2008) and Shooshtarian (2010) observed increased proline content under water shortage in ornamental turf grasses and various species of ground covering plants. In the Sedum taxa studied in the present work, however, the relative stress-induced increase in Pro contents was negatively correlated to the relative degree of tolerance: it was the largest in the most sensitive species, S. album, followed by S. sediforme, whereas no significant change was observed for the most tolerant S. spurium. Negative correlations between Pro accumulation and the relative degree of tolerance have been reported for other taxa, for example for different bean cultivars (Morosan et al. 2017). In any case, Pro concentrations measured in all four Sedum species were too low, both in the controls and the stressed plants, to have any relevant osmotic effect. Nevertheless, this does not exclude the participation of Pro in drought tolerance mechanisms, directly protecting cell membranes as low-molecular-weight chaperon or indirectly as ROS scavenger (Chen and Murata 2002; Szabados and Savoure 2010; Moustakas et al. 2011). Although Pro concentrations under water stress conditions were similar for the four Sedum 
taxa, control values in $S$. spurium and $S$. ochroleucum were significantly higher than in $S$. sediforme and S. album, suggesting the presence of constitutive mechanisms that could contribute to the higher tolerance of the two former species.

Regarding the accumulation of soluble sugars, our data do not support a functional role of these compounds in drought tolerance mechanisms in Sedum, since the highest levels were measured in the most sensitive taxa, S. album and S. sediforme. . The observed increase may result from enhanced synthesis of sugars directed to sustain metabolic activity of stressed cells (Chavez et al. 2009), rather than from a role in osmotic adjustment. This notion is supported by the fact that in the more tolerant $S$. spurium and $S$. ochroleucum the concentrations of soluble sugars did not change significantly, regardless of the water regime.

We are aware that there are some contradictory data in the literature, regarding the reported drought tolerance of different sedums. For instance, $S$. spurium was classified as a suitable plant to be grown in conditions of limited water supply (Getter and Rowe 2008), in agreement with our own results. Yet Nagase and Dunnet (2010) found it to be less tolerant to water deficit than other species, including S. album, contrary to the data presented here - and also to those of Starry et al. (2014).. Furthermore,several reports indicated that S. sediforme was able to survive under minimal or no irrigation (Monterusso et al. 2005; Nektarios et al. 2015), while the genotype used in our study was relatively sensitive to water stress. In all referenced reports, different ornamental Sedum cultivars were used, and the observed differences in the responses to the applied stress may be related to their genetic and ecological diversity. There are evidences that some Sedum species possess a high genetic variability and quite easily develop into subspecies, as in the case of $S$. ochroleucum subsp. mediterraneum (Gallo 2014). This variability may influence facultative activation of CAM metabolism and photosynthetic plasticity (Gravatt and Martin 1992; Castillo, 1996), or increase the antioxidant activity in the specimens subjected to stresses, which in turn could affect stress tolerance. Therefore, the screening for drought tolerance of Sedum taxa, to select the most resistant, should be performed not only comparing different species within the genus, but also different genotypes/ecotypes within single Sedum species..

\section{Conclusions}

Owing to their decorative value, succulence and specific metabolic traits, the Sedum species studied here are valuable plant material ready to be exploited as ornamentals and, more specifically, in technology for urban horticulture. Here, we have established the relative level 
of tolerance to drought stress in four different species. Although the tolerance of succulent plants to water deficit is known, comparative studies focusing on the responses of Sedum spp. to water stress and the identification of suitable biochemical markers of drought tolerance in this genus, are still limited. A deep understanding of ecophysiological aspects of drought tolerance mechanisms should help to establish more efficient screening techniques aiming at the selection of resistant genotypes. Our results revealed several suitable indicators of the degree of tolerance/sensitivity to water stress: higher tolerance appears to be associated to a relatively low degradation of photosynthetic pigments (specially carotenoids), the lack of stress-induced accumulation of MDA and antioxidant compounds, and relatively higher constitutive levels of Pro in the absence of stress. These findings may allow setting up protocols for the quick evaluation of drought tolerance in the numerous representatives of the Sedum genus, especially in the case of various ecotypes within particular species, which are usually morphologically similar, but may substantially differ in their reaction to water deficit.

\section{References}

Ahmad P., Jaleel C.A., Salem M.A., Nabi G., Sharma S., 2010. Roles of enzymatic and nonenzymatic antioxidants in plants during abiotic stress. Crit. Rev. Biotechnol. 30(3), 161-175. Al Hassan M., Martınez Fuertes M., Ramos Sánchez F.J., Vicente O., Boscaiu M., 2015. Effects of salt and water stress on plant growth and on accumulation of osmolytes and antioxidant compounds in cherry tomato. Not. Bot. Hort. Agrobot. Cluj-Napoca 43(1), 1-11. Al Hassan M., Estrelles E., Soriano P., López-Gresa M. P., Bellés J.M., Boscaiu M., Vicente O. 2017. Unraveling Salt Tolerance Mechanisms in Halophytes: A Comparative Study on Four Mediterranean Limonium Species with Different Geographic Distribution Patterns. Frontiers in Plant Science. doi: 10.3389/fpls.2017.01438

Al-Qudah M.A., Muhaidat R., Alomary A.A., Malkawi E.H., Al-Jaber H.I., Trawenh I.N., Abu Zarga M.H., Abu Orabi S.T., 2012. Investigating the chemical composition and the antimicrobial activity of the essential oil and Crude Extracts of Sedum. Pharm. J. 4 (33), 1-6. Anjum S.A., Farooq, M., Xie, X.Y., Liu, X.J., Ijaz, M.F., 2012. Antioxidant defense system and proline accumulation enables hot pepper to perform better under drought. Sci. Hort. 140, 66-73. 
Apel K., Hirt H., 2004. Reactive oxygen species: metabolism, oxidative stress, and signal transduction. Ann. Rev. Plant Physiol. 55(1), 373-399.

Bachereau F., Marigo G., Asta J., 1998. Effect of solar radiation (UV and visible) at high altitude on CAM cycling and phenolic compound biosynthesis in Sedum album. Physiol. Plant. 104 (2), 203-2010.

Bates L.S., Waldren R.P., Teare I.D., 1973. Rapid determination of free proline for water stress studies. Plant Soil 39, 205-207.

Batra N.G., Sharma V., Kumari N., 2014. Drought-induced changes in chlorophyll fluorescence, photosynthetic pigments, and thylakoid membrane proteins of Vigna radiata. $\mathrm{J}$ Plant Interact. 9, 712-721.

Bartlett M.K., Scoffoni C., Sack L., 2012. The determinants of leaf turgor loss point and prediction of drought tolerance of species and biomes: a global meta-analysis. Ecol. Let. 15, 393-405.

Basu S., Roychoudhury A., Saha P. P., Sengupta D. N., 2010. Differential antioxidative responses of indica rice cultivars to drought stress. Plant Growth Reg. 60(1), 51.

Bautista I., Boscaiu M., Lidon A., Llinares J.V., Lull C., Donat M.P., Mayoral O., Vicente O., 2016. Environmentally induced changes in antioxidant phenolic compounds levels in wild plants. Acta Physiol. Plant. 38, 9. doi: 10.1007/s11738-015-2025-2

Blainski A., Lopes G.C., Palazzo de Mello J.C., 2013. Application and analysis of the Folin Ciocalteu method for the determination of the total phenolic content from Limonium. brasiliense L. Molecules 18 (6), 6852-6865.

Blum A., 2011. Drought Resistance and Its Improvement. In: Plant Breeding for WaterLimited Environments. Springer, New York, NY.

Cai X., Zhang X., Noël P.H., Shafiee-Jood M., 2015. Impacts of climate change on agricultural water management: a review. WIREs Water 2, 439-455. Doi:10.1002/wat2.1089 Carter T., Butler C., 2008, Ecological impacts of replacing traditional roofs with green roofs in two urban areas. Cities Environ. 1 (2), Article 9.

Castillo F.J., 1996. Antioxidative protection in the inducible CAM plant Sedum album L. following the imposition of severe water stress and recovery. Oecologia 107(4), 469-477. 
Cicevan R., Al Hassan M., Sestras A.F., Prohens J., Vicente O., Sestras R.E., Boscaiu M., 2016. Screening for drought tolerance in cultivars of the ornamental genus Tagetes (Asteraceae). Peer J. DOI 10.7717/peerj.2133

Chaves M.M., Oliveira M.M., 2004. Mechanisms underlying plant resilience to water deficits:prospects for water-saving agriculture. J. Exp. Bot. 55(407), 2 365-2384.

Chen T. H., Murata N., 2002. Enhancement of tolerance of abiotic stress by metabolic engineering of betaines and other compatible solutes. Cur. Op. Plant Biol. 5(3), 250-257.

Chen Z., Cuin TA., Zhou M., Twomei A., Naidu B.P., Shabala S., 2007. Compatible solute accumulation and stress-mitigating effects in barley genotypes contrasting in their salt tolerance. J. Exp. Bot. 58(15/16), 4245-4255.

Das K., Roychoudhury A., 2014. Reactive oxygen species (ROS) and response of antioxidants as ROS-scavengers during environmental stress in plants. Front. Environ. Sci.

https://doi.org/10.3389/fenvs.2014.00053

Dubois M., Gilles K.A., Hamilton J.K., Reberd P.A., Smith F., 1956. Colorimetric method for determination of sugars and related substances. Anal. Chem. 28, 350-356.

Damas O., Donvez J., Ferrando D., Ferre A., Marqueyssat P., Delhommeau P., 2010.

Identification of plant ranges adapted to water limited conditions of green roofs: a case study from France. Conference Material: World Green Roof Congress, 15-16 September 2010, London.

De Diego N., Sampedro M.C., Barrio R.J., Saiz-Fernandez I., Moncalean P., Lacuesta M., 2013. Solute accumulation and elastic modulus changes in six radiata pine breeds exposed to drought. Tree Physiol. 33, 69-80.

Del Rio D., Stewart A.J., Pellegrini N., 2005. A review of recent studies on malondialdehyde as toxic molecule and biological marker of oxidative stress. Nut. Met. Card. Dis. 15, 316-328.

Devi M. A., Giridhar P., 2015. Variations in physiological response, lipid peroxidation, antioxidant enzyme activities, proline and isoflavones content in soybean varieties subjected to drought stress. Proceedings of the National Academy of Sciences, India Section B: Biol. Sci. 85(1), 35-44. 
Durhman A.K, Rowe D.B., Rugh C.L., 2006. Effect of watering regimen on chlorophyll fluorescence and growth of selected green roof plant taxa. HortSci. 41 (7), 1623-1628.

Farooq M., Wahid A., Kobayashi N., Fujita D., Basra S.M.A., 2009. Plant drought stress: effects, mechanisms and management. Agro. Sustain. Dev. 29, 185-212.

Gallo L., 2014. Sedum ochroleucum subsp. mediterranean (Crassulaceae), a new Italian endemic. Willdenowia 44(1), 27-33. https://doi.org/10.3372/wi.44.44104

Getter K. L., Rowe D. B., 2006. The role of extensive green roofs in sustainable development. Hort. Sci. 41(5), 1276-1285.

Gholami M., Rahemi M., Kholdebarin B., Rastegar S., 2012. Biochemical responses in leaves of four fig cultivars subjected to water stress and recovery. Sci. Hort. 148, 109-117.

Giannakopoulos C., Le Sager P., Bindi M., Moriondo M., Kostopoulou E., Goodess C.M., 2009. Climatic changes and associated impacts in the Mediterranean resulting from a $2^{\circ} \mathrm{C}$ global warming. Global Planet. Chan. 68(3), 209-224.

Gil R., Boscaiu M., Lull C., Bautista I., Lidón A., Vicente O., 2013. Are soluble carbohydrates ecologically relevant for salt tolerance in halophytes? Fun. Plant Biol. 40, 805818.

Gil R., Bautista I., Boscaiu M., Lidón A., Wankhade S., Sanchez H., Llinares J., Vicente O., 2014. Responses of five Mediterranean halophytes to seasonal changes in environmental conditions. AoB Plants. DOI 10.1093/aobpla/plu049.

Gravatt D.A., Martin C.E. 1992. Comparative ecophysiology of 5 species of Sedum (Crassulaceae) under well-watered and drought-stressed conditions. Oecologia 92 (4), $532-$ 541.

Han J., Zhao L., 2005. Research progress of Sedum plants. J. Anhui Agri. Sci. 33 (11), 21292130 .

Hare P.D., Cress W.A., van Staden J., 1999. Proline synthesis and degradation: a model system for elucidating stress-related signal transduction. J. Exp. Bot. 50, 413-434.

Hart H., Bleij B., 2003, Sedum. In: Eggli U. (ed.) Illustrated handbook of succulent plants: Crassulaceae. Springer, Berlin,. Heidelberg \& New York: pp. 235-332 
Hastilestari B. R., Mudersbach M., Tomala F., Vogt H., Biskupek-Korell B., Van Damme P., Papenbrock J., 2013. Euphorbia tirucalli L. - Comprehensive characterization of a drought tolerant plant with a potential as biofuel source. PLoS one, 8(5), e63501.

Hoagland, D.R.; Arnon, D.I. The water-culture method for growing plants without soil. Circ. Califor. Agric.Exp. Stat. 1950, 347, 32-63.

Hodges D.M., DeLong J.M., Forney C.F., Prange R.K., 1999. Improving the thiobarbituric acid reactive-substances assay for estimating lipid peroxidation in plant tissues containing anthocyanin and other interfering compounds. Planta 207, 604-611.

Jalas J., Suominen J., Lampinen R., Kurtto A. (ed.) 1999: Atlas florae Europaeae.

Distribution of vascular plants in Europe. 12. Resedaceae to Platanaceae. Helsinki: The Committee for Mapping the Flora of Europe and Soc. Biol. Fen. Van.

Ji K., Wang Y., Sun W., Lou Q., Mei H., Shen S., Chen H., 2012. Drought-responsive mechanisms in rice genotypes with contrasting drought tolerance during reproductive stage. J. Plant Physiol. 169(4), 336-344.

Jin R., Shi H., Han Ch., Zhong B., Wang Q., Chan Z., 2015. Physiological changes of purslane (Portulaca oleracea L.) after progressive drought stress and rehydration. Sci. Hort. $194,215-221$.

Karahan F., Oz I., Demircan N., Stephenson R., 2006. Succulent plant diversity in Turkey: Stonecrops (Crassulaceae). Haseltonia 12, 41-54.

Khan N., Naqvi F.N., 2010. Effect of water stress on lipid peroxidation and antioxidant enzymes in local bread wheat hexaploids. J. Food Agri. Environ. 8, 521-526.

Kuronuma T., Watanabe H., 2017. Photosynthetic and transpiration rates of three Sedum species used for green roofs. Environ. Contr. Biol. 55 (3), 137-141.

Lichtenthaler H.K., Wellburn, A.R., 1983. Determinations of total carotenoids and chlorophylls a and b of leaf extracts in different solvents. Bioch. Soc.

Transactions 11, 591-592. doi: 10.1042/bst0110591.

Lopez-Nicolas A., Pulido-Velazquez M., Rougé C., Harou J.J., Escriva-Bou A., 2018. Design and assessment of an efficient and equitable dynamic urban water tariff. Application to the city of Valencia, Spain. Environ. Mod. Software 101: 137-145. 
Liu C., Liu Y., Guo K., Fan D., Li G., Zheng Y., Yang, R., 2011. Effect of drought on pigments, osmotic adjustment and antioxidant enzymes in six woody plant species in karst habitats of southwestern China. Environ. Exp. Bot. 71(2), 174-183.

Mathur S., Agrawal D., Jajoo A., 2014. Photosynthesis: Response to high temperature stress. J. Photochem. Photobiol. B: Biol. 137, 116-126.

Mori I. C., Utsugi S., Tanakamaru S., Tani A., Enomoto T., Katsuhara M., 2009. Biomarkers of green roof vegetation: anthocyanin and chlorophyll as stress marker pigments for plant stresses of roof environments. J. Environ. Eng. Man. 19(1), 21-27.

Morosan, M., Al Hassan, M., Naranjo, M.A., López-Gresa, M.P., Boscaiu, M., Vicente, O., 2017. Comparative analysis of drought responses in Phaseolus vulgaris (common bean) and P. coccineus (runner bean) cultivars. The EuroBiotech J. 1 (3), doi:10.24190/ISSN2564 $615 X / 2017 / 03.09$

Monterusso M.A., Rowe D.B., Rugh C.L., 2005. Establishment and persistence of Sedum spp. and native taxa for green roof applications. HortSci. 40 (2), 391-396.

Moustakas M., Sperdouli I., Kouna T., Antonopoulou C. I., Therios I., 2011. Exogenous proline induces soluble sugar accumulation and alleviates drought stress effects on photosystem II functioning of Arabidopsis thaliana leaves. Plant Growth Reg. 65(2), 315. Nagase A., Dunnett N., 2010. Drought tolerance in different vegetation types for extensive green roofs: Effect of watering and diversity. Land. Urban Plan. 97, 318-327.

Nektarios P.A., Ntoulas N., Nydrioti E., Kokkinou I., Bali E., Amountzias I., 2015. Drought stress response of Sedum sediforme grown in extensive green roof systems with different substrate types and depths. Sci. Hort. 181, 52-61.

Nikulin V.Y., Gontcharova S.B., Stephenson R., Gontcharov A.A., 2016. Phylogenetic relationship between Sedum L. and related genera (Crassulaceae) based on ITS rDNA sequence comparisons. Flora 224, 218-229.

Oliver M.J., Cushman J.C., Koster K.L., 2010. Dehydration tolerance in plants. Methods Mol Biol. 639, 3-24.

Ortega-Gómez T., Pérez-Martín M.A., Estrela T., 2018. Improvement of the drought indicators system in the Júcar River Basin, Spain. Sci. Total Enviro. 610-611, 276-290. 
Osakabe Y., Osakabe K., Shinozaki K., Tran L., 2014. Response of plants to water stress. Frontiers Plant Sci. doi: 10.3389/fpls.2014.00086

Per TS., Khan N.A., Reddy P.S., Masood A., Hasanuzzaman M., Khan M.I.R., Anjum N., A., 2017. Approaches in modulating proline metabolism in plants for salt and drought stress tolerance: Phytohormones, mineral nutrients and transgenics. Plant Physiol. Biochem. 115, 126-140.

Pudelska K., Rojek K., 2015. The period of flower carpets and other cilorful garden decorations i.e. Kinds of ornamental species used in Europe at the turn of $20^{\text {th }}$ century. Tech. Transact. Architecture 10A, 21-32, DOI: 10.4467/2353737CT.15.151.4188

Rabbani G., Choi I., 2018. Roles of osmolytes in protein folding and aggregation in cells and their biotechnological applications. Internat. J. Biol. Macro. 109, 483-491.

Sánchez-Rodríguez E., Moreno D. A., Ferreres F., del Mar Rubio-Wilhelmi M., Ruiz J. M., 2011. Differential responses of five cherry tomato varieties to water stress: changes on phenolic metabolites and related enzymes. Phytochem. 72(8), 723-729.

Sandoval J.F., Yoo C.Y., Gosney M.J., Mickelbart M.V., 2016. Growth of Arabidopsis thaliana and Eutrema salsugineum in a closed growing system designed for quantification of plant water use. J. Plant Physiol. 193, 110-118.

Selahvarzi Y., Tehranifar A., Gezanchian A., 2008. Phyisomorphological changes under drought stress and rewatering in endemic and exotic turfgrasses. Iran. J. Sci. Tech. Hort., 9(3), 193-204.

Shooshtarian S., 2010. Physiological and ecological investigation of some groundcover plants in greenspace of Kish Island. MSc Thesis. Horticulture Engineering. Agriculture Faculty. Shiraz University, p. 168.

Shooshtarian S., TehraniFar A., Ghani A., Kiani M., 2011. Effects of irrigation frequency regimes on morphological and physiological characteristics of six sedum species. African J. Agric. Res. 6 (26), 5694-5700.

Starry O., Lea-Cox J. D., Kim J., Van Iersel M.W., 2014. Photosynthesis and water use by two Sedum species in green roof substrate. Environ. Exp. Bot. 107, 105-112.

Stephenson R. 1994. Sedum cultivated stonecrops. Timber Press, Portland, Oregon. 
Stevens JF., Hart HT., Pouw A., Block A., Zwaving JH., 1994. Epicuticular waxes of Sedum series Rupestria. Phytochem. 36, 341-8.

Stevens J.F., Hart H.T., Elema E.T., 1996. Flavonoid variation in Eurasian Sedum and Sempervivum. Phytochem. 41, 503-12.

Szabados L., Savoure A., 2010. Proline: a multifunctional amino acid. Trends Plant Sci. 15(2), 89-97.

Talukdar D., 2013. Comparative morpho-physiological and biochemical responses of lentil and grass pea genotypes under water stress. J. Natural Sci. Biol. Med. 4(2), 396-402.

The Plant List. 2013. The Plant List: a working list of all plant species. Version 1.1. Available at http://www.theplantlist.org (accessed 12 January 2016).

Thiede J., Eggli U., 2007. Crassulaceae. K. Kubitzki (ed.), The families and genera of vascular plants, Vol. 9, Springer, Berlin Heidelberg, pp. 83-118.

Thomas H., 1997. Drought resistance in plants, In: S.D. Amarjit, K.B. Ranjit (eds.), Mechanisms of Environmental Stress Resistance in Plants, Harwood, pp. 1-42.

Thorne R.F., Reveal J.L., 2007. An updated classification of the class Magnoliophyta ("Angiospermae"). Bot. Rev. 73, 67-181.

Wang S., Liang D., Li C., Hao Y., Ma F., Shu H. 2012. Influence of drought stress on the cellular ultrastructure and antioxidant system in leaves of drought-tolerant and droughtsensitive apple rootstocks. Plant Physiol. Biochem. 51, 81-89.

Vahdati N., Tehranifar A., Kazemi F., 2017. Assessing chiling and drought tolerance of different plant genera on extensive green roofs in arid climate region of Iran. J. Environ. Manag. 192, 215-223.

Van Mechelen C., Dutoit T., Hermy M., 2014. Mediterranean open habitat vegetation offers great potential for extensive green roof design. Land. Urban Plan. 121, 81-91.

Vijayaraghavan K., 2016. Green roofs: A critical review on the role of components, benefits, limitations and trends. Re. Sustain. Energy Rev. 57, 740-742.

Xu T., Wang Z., Lei T., Lv C., Wang J., Lu J., 2015. New flavonoid glycosides from Sedum aizoon L. Fitoter. 101, 125-132. 
Yayli N., Yasar A., Yilmaz I. N., Yayli N., Cansu T.B., Coskuncelebi K., Karaoglu S., 2010. Chemical constituents and antimicrobial activities of the essential oils from Sedum pallidum var. bithynicum and S. spurium grown in Turkey, Pharmaceut. Biol. 48(2), 191-194.

Yooyongwech S., Theerawitaya C., Samphumphuang T., Cha-um S., 2013. Water-deficit tolerant identification in sweet potato genotypes (Ipomoea batatas (L.) Lam.) in vegetative developmental stage using multivariate physiological indices. Sci. Hort. 162, 242-251.

You J., Chan Z., 2015. ROS regulation during abiotic stress responses in crop plants. Front. Plant Sci. 6, 1092.

Zhishen J., Mengcheng T., Jianming W., 1999. The determination of flavonoid contents in mulberry and their scavenging effects on superoxide radicals. Food Chem. 64, 555-559. 

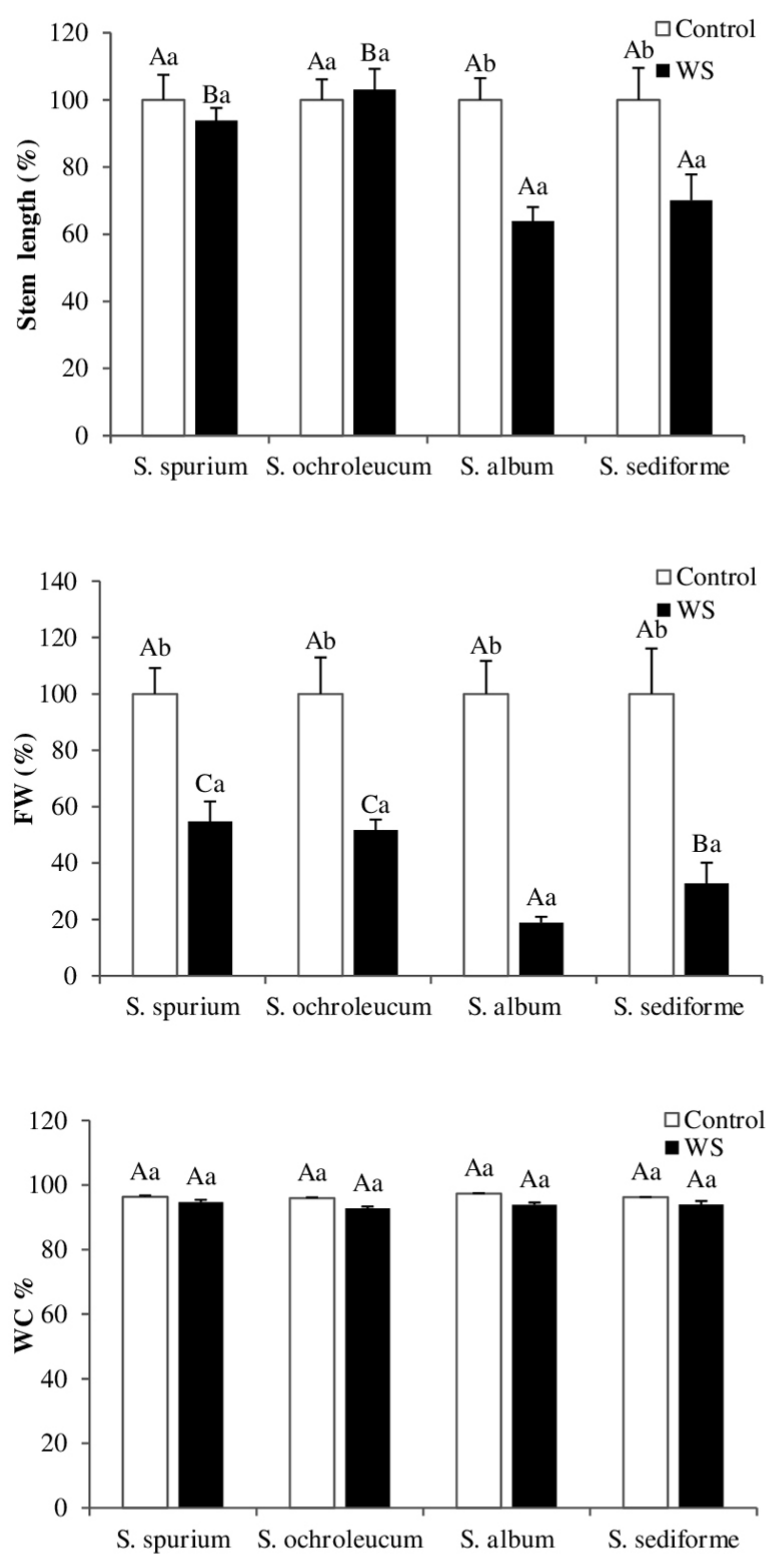

Ryc. 1 Average stem length (\%) (A), fresh weight (FW\%) (B) and relative water content (WC\%) (C) as a percentage of the fresh weight ratio in the leaves of Sedum species after 4 weeks of water stress. Values shown are means \pm SD $(n=6)$. For each species, different lowercase letters indicate significant differences among treatments and different capital letters indicate significant differences among species undergoing the same treatment, according to Tukey's test $(\alpha=0.05)$. 

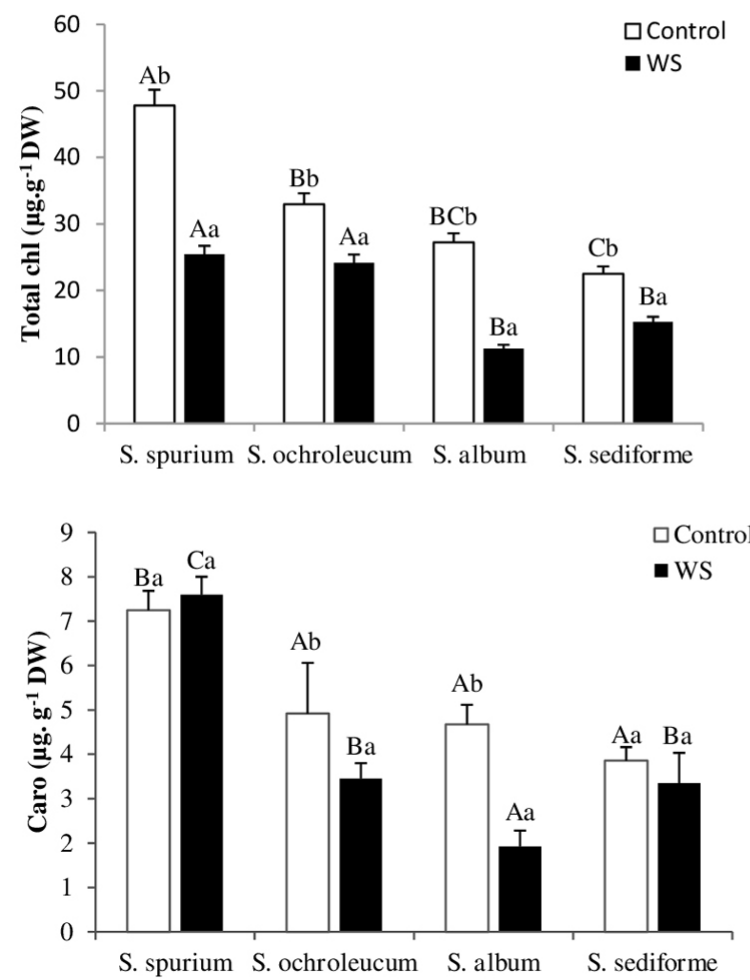

Ryc. 2 Total chlorophyll content (Total chl) (A) and total carotenoids (Caro) (B) contents in the leaves of Sedum species, after 4 weeks of water stress. Values shown are means $\pm \operatorname{SD}(n=6)$. For each species, different lowercase letters indicate significant differences among treatments and different capital letters indicate significant differences among species undergoing the same treatment, according to Tukey's test $(\alpha=0.05)$. 

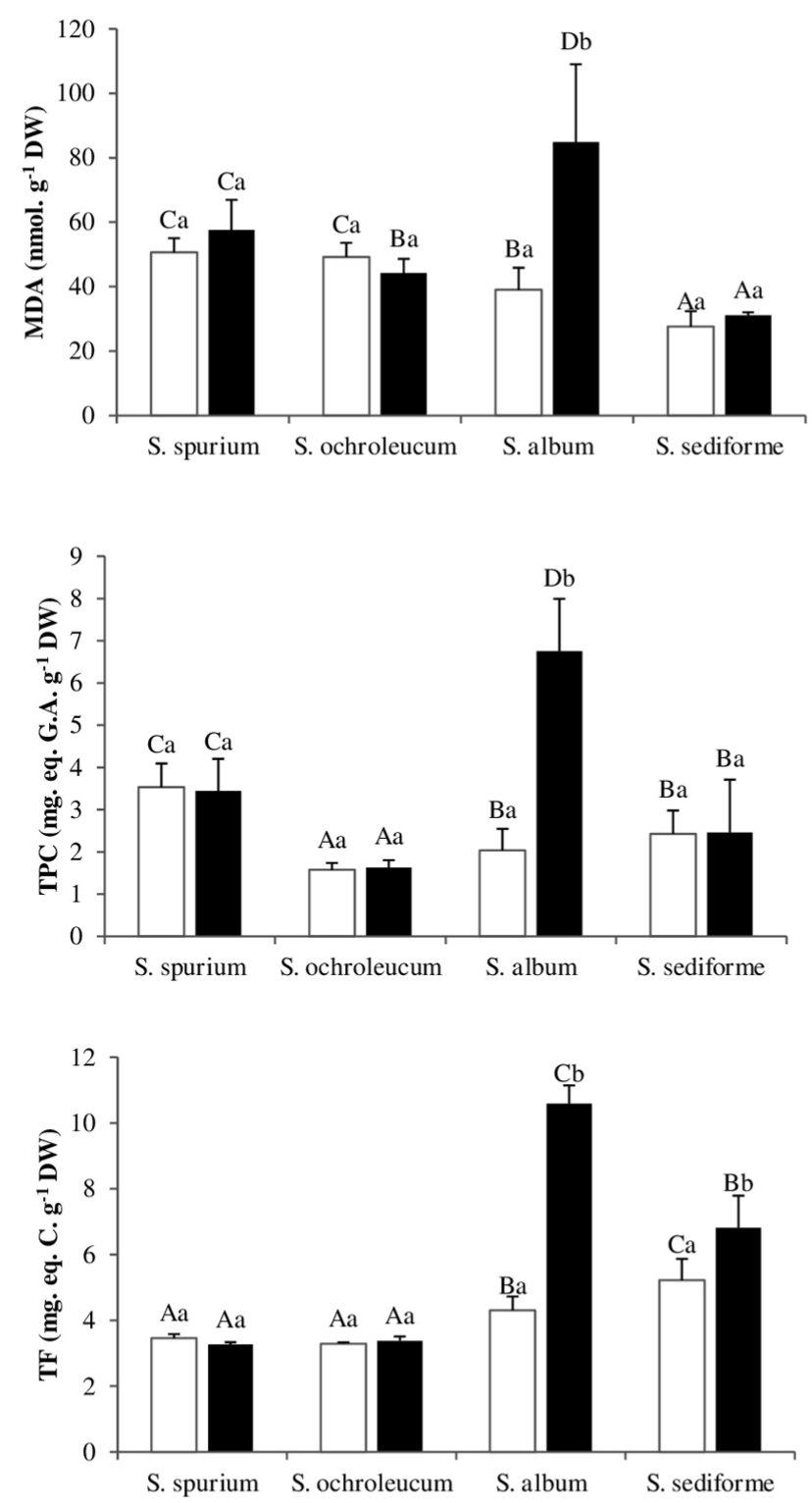

Ryc. 3 Malondialdehyde (MDA) (A), total phenolic compounds (TPC) (B) and total flavonoids (TF) (C) accumulation in the leaves of Sedum species after 4 weeks of water stress. Values shown are means $\pm \operatorname{SD}(n=6)$. For each species, different lowercase letters indicate significant differences among treatments and different capital letters indicate significant differences among species undergoing the same treatment, according to Tukey's test $(\alpha=0.05)$. 

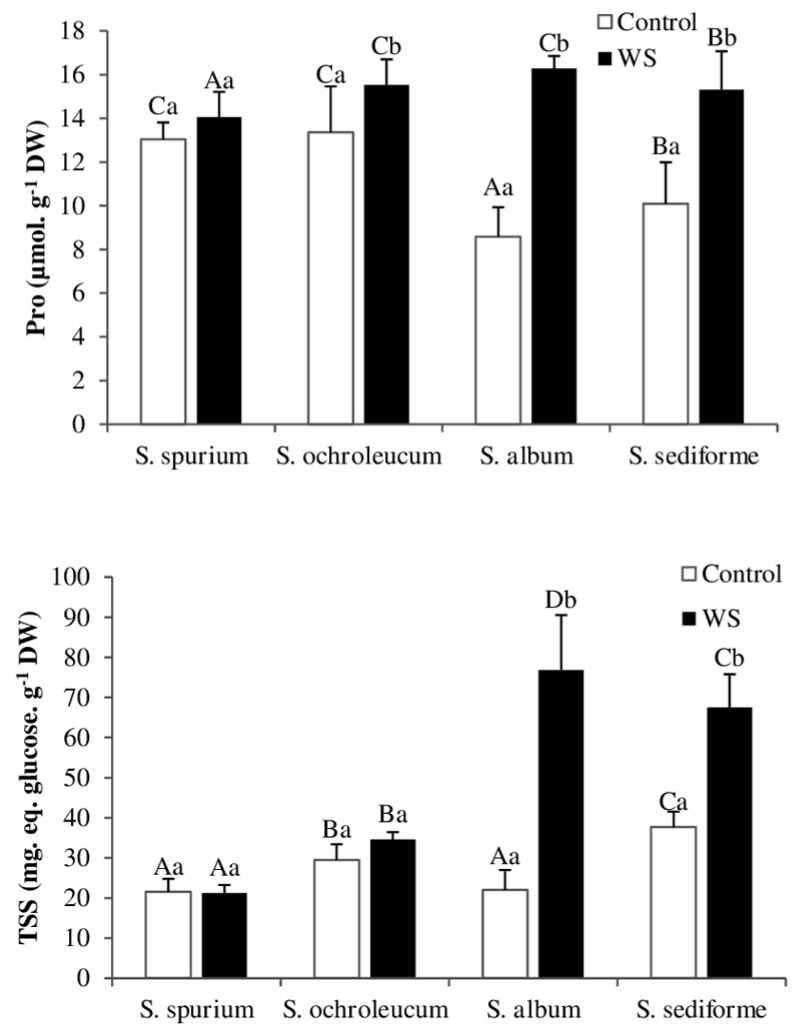

Ryc. 4 Proline (Pro) (A), total soluble sugars (TSS) (B) in the leaves of Sedum species after 4 weeks of water stress. Values shown are means $\pm \operatorname{SD}(n=6)$. For each species, different lowercase letters indicate significant differences among treatments and different capital letters indicate significant differences among species undergoing the same treatment, according to Tukey's test $(\alpha=0.05)$. 